\title{
Proposta de uma trilha interpretativa na Reserva Particular do Patrimônio Natural Estadual Mo'ã, Itaara (RS)
}

\section{Proposal for an Interpretative Trail in The Particular Reservation of The Natural Heritage State Mo'ã, Itaara (RS, Brazil)}

\section{Letícia Ramires Corrêa, Adriano Severo Figueiró}

\section{RESUMO}

O presente trabalho tem como objetivo propor uma estratégia de leitura da paisagem por meio de uma trilha interpretativa na RPPN Estadual MO'Ã, que se localiza no município de Itaara (RS). Por meio desta proposta, pretendese ressaltar a valorização e preservação do patrimônio natural presente na RPPN, por meio da Interpretação Ambiental, cuja o objetivo principal é a tradução de informações relacionadas a natureza partindo do contato direto com o meio ambiente. Instituída em 15 de junho de 2015, a RPPN Estadual MO'Ã, busca promover a proteção dos recursos ambientais e a conservação da diversidade biológica, permitindo visitação e atividades que envolvam Educação Ambiental. Sendo assim a presença de uma Unidade de Conservação no município de Itaara abre espaço para práticas de Interpretação Ambiental (IA), que permitam uma maior aproximação da sociedade com a natureza. Para isso buscou-se utilizar a metodologia sistêmica, pois para haver IA tem-se que compreender todos os elementos e suas relações entre si, para traduzi-las ao visitante. Portanto, os resultados obtidos após três saídas de campo, permitiram que se elegesse como eixo principal da interpretação a mata ciliar, localizado ao sul da propriedade, justamente pela sua dinâmica peculiar, transformadora da paisagem em períodos de elevada pluviosidade. Optou-se por abordar o tema sobre a importância da mata ciliar, assim como a energia do rio. Foram elencados 6 pontos a partir do método do IAPI para uma trilha autoguiada de $1,5 \mathrm{Km}$ no entorno do rio que faz a divisa da RPPN Estadual MO'Ã com outra propriedade. $O$ meio interpretativo escolhido foi o folder e um Guia prático, a fim de atribuir autonomia ao visitante em escolher os pontos de seu interesse e possibilidade de guardar as informações e interpretá-las.

PALAVRAS-CHAVE: Interpretação Ambiental; RPPN Estadual MO'Ã; Trilha interpretativa; Patrimônio Natural. 


\section{ABSTRACT}

The present work aims to propose a strategy of reading the landscape by means of an interpretative trail in the RPPN Estadual MO'Ã, which is located in the municipality of Itaara (RS, Brazil). Through this proposal, it is intended to highlight the valuation and preservation of the natural heritage present in the RPPN, through the Environmental Interpretation, whose main objective is the translation of information related to nature starting from direct contact with the environment. Established on June 15, 2015, the State MOH RPPN seeks to promote the protection of environmental resources and the conservation of biological diversity, allowing for visitation and activities that involve Environmental Education. Thus, the presence of a Conservation Unit in the municipality of Itaara opens up space for Environmental Interpretation (IA) practices, which allow a closer relationship between society and nature. For this, we tried to use the systemic methodology, because in order to have Al we have to understand all the elements and their relationships with each other, to translate them to the visitor. Therefore, the results obtained after three field trips allowed the selection of the riparian forest, located south of the property, due to its peculiar dynamics, transforming the landscape into periods of high rainfall. It was decided to approach the theme about the importance of the riparian forest, as well as the energy of the river. Six points were listed from the IAPI method for a self-guided trail of $1.5 \mathrm{Km}$ in the vicinity of the river that makes the boundary of the State RPPN MO'Ã with another property. The interpretive medium chosen was the folder and a practical guide, in order to give the visitor autonomy in choosing the points of their interest and possibility to store the information and interpret them.

KEYWORDS: Environmental Interpretation; State RPPN MO'Ã; Interpretive Trail; Natural Patrimony.

\section{Introdução}

O grande desafio da humanidade, na atualidade, é compreender sua intrínseca relação e dependência ao meio natural. Assim como outras civilizações romperam com os limites da resiliência dos sistemas naturais, com gravíssimas consequências para o suporte da vida humana, de certa forma estamos hoje vivenciando uma crise socioambiental gerada pela relação de exploração que estabelecemos com a natureza. A partir deste distanciamento o homem promoveu esta exploração dos "recursos naturais" em nome do desenvolvimento econômico ilimitado, caminhando assim para uma profunda crise ambiental (SOUZA, 2014).

Por traz desta crise socioambiental está a crise de percepção, onde a humanidade está se afastando da natureza e rompendo seus laços vitais com o meio natural, desequilibrando-se e, assim, comprometendo até mesmo suas relações sociais. Isto desencadeia uma série de conflitos, o que nos leva a considerar que fazemos parte da natureza, de tal maneira que, ao se degradarem fisicamente as estruturas da natureza, compromete-se, também, a estabilidade da sociedade. Assim, é considerável que os 
problemas atuais não podem ser estudados e resolvidos de forma isolada, mas sistêmica e interdependente como aborda Capra (1996).

Diante das transformações humanas nas paisagens naturais surge a necessidade da criação de medidas de gestão e planejamento que venham a proteger e destacar as potencialidades paisagísticas do território nacional. Neste sentido, a instituição de áreas protegidas visando à conservação das características naturais é um dos principais instrumentos da Política Nacional do Meio Ambiente e uma das estratégias do poder público para assegurar a manutenção da qualidade ambiental e, consequentemente, da qualidade de vida da população (KORMANN et al., 2010). Sendo assim há a possibilidade de aproximar as comunidades com a natureza através das Unidades de Conservação, a partir da interpretação ambiental, a fim de redescobrir o sentido da natureza, pois abre o espaço para a divulgação e incentivo à conservação, e constrói um aprendizado a partir de recreação junto à natureza, restaurando a percepção antes perdida.

Nesse sentido a Reserva Particular do Patrimônio Natural Estadual MO'Ã, localizada em Itaara (RS), contribui com uma área natural propicia para uma interpretação ambiental, onde o visitante pode interagir e se apropriar do conhecimento sobre o patrimônio natural que esta Reserva oferece.

Sendo assim, busca-se através do referente trabalho propor uma trilha interpretativa na RPPN MO'Â, para que seu patrimônio natural seja traduzido a partir de uma linguagem adequada ao público que irá buscar uma aproximação com a natureza e seus recursos especialmente no caso das escolas de Itaara. A interpretação aqui entendida seria a leitura e compreensão não apenas imediata da paisagem, mas aquela capaz de despertar a curiosidade e emancipar o indivíduo, a ponto de mudar suas atitudes perante o mundo.

\section{Objetivo Geral}

Propor uma estratégia de leitura da paisagem da RPPN MO'Ã em Itaara (RS), por meio da interpretação ambiental em uma trilha autoguiada.

\section{Metodologia}

Diante da complexidade de propor uma leitura da paisagem da RPPN Estadual MO'Ã através da IA, o que melhor atende as necessidades desta pesquisa é a abordagem sistêmica, onde distinguir um sistema na multiplicidade dos fenômenos da superfície é ato mental, cuja ação procura abstrair o referido sistema da realidade evolvente (CHRISTOFOLETTI, 1979), ou seja, busca estabelecer os elementos existentes e suas relações.

$\mathrm{Na}$ primeira etapa buscou-se apresentar uma revisão bibliográfica a respeito do conceito de interpretação ambiental e sua correlação com as Unidades de Conservação, a partir de bibliografia de Thomas et al. (2011), Kormann et al. (2010) e Ferrarese (2016) as quais durante anos realizaram pesquisas na RPPN Estadual MO'Ã subsidiando sua instituição e 
contribuindo para esta pesquisa com a caracterização da área e Tilden (1957) e o Manual de Introdução à Interpretação Ambiental do Projeto Doces Matas (2002) e o material Manejo de Trilhas: um manual para gestores (2008) como base fundamental para compreender a IA, assim como as etapas para escolher o tema, os tópicos e os meios de interpretação.

Na segunda etapa partiu-se para as saídas a campo e investigação in loco da RPPN Estadual MO'Ã. A partir disso, foi determinado o tema central da trilha que é "Mata Ciliar".

Foram selecionados 6 pontos para interpretação ambiental a partir da metodologia dos Indicadores de Atratividade de Pontos Interpretativos (IAPI) "que objetiva agregar ao potencial interpretativo de cada sítio selecionado, um valor qualitativo para aumentar a atratividade do local' (MAGRO; FREIXÊDAS,1998). Primeiramente foram coletados 10 pontos com GPS (Global Positioning System, modelo Garmin eTrex 30), e foram transferidos para o computador com o auxílio do programa Trake Maker, e visualizados utilizando o programa Google Earth, os registros fotográficos foram realizados com câmera NIKON COOLPIX L330, 20.2 Megapixels e descritos. $\mathrm{Na}$ segunda fase organizou-se um quadro com indicadores de atratividade. $\mathrm{Na}$ terceira fase construiu-se uma Ficha de campo que foi preenchida indicando a presença ou ausência de cada indicador e a pontuação final (Quadro 1).

Quadro 1: Ficha de campo com indicadores de atratividade. Os números entre parênteses indicam o peso atribuído aos indicadores selecionados, podendo variar para cada trilha.

Table 1: Field sheet with indicators of attractiveness. The numbers in parentheses indicate the weight assigned to the selected indicators, and may vary for each track.

\begin{tabular}{|c|c|c|c|c|c|c|c|c|c|c|c|c|c|}
\hline $\mathrm{N}^{\circ} \mathrm{Tem}$ & $\begin{array}{l}\text { Linhis } \\
V\end{array}$ & Linha & & Posiça & & & alaidistank & & Ne & & Rocha & Epinita & Pontuaçáo \\
\hline & (1) & 1) & Mlue: 1 | & Inferior(1) & Superigr 2) & $19 p\left|a r g^{\prime} 2\right\rangle$ & Mécio(1) & Fuado(3) & Ysuall3) & $\operatorname{sen} 22)$ & (2) & (2) & \\
\hline Arroio & & $x$ & & & $x$ & & $x$ & $x$ & $x$ & $x$ & $x$ & & 16 \\
\hline RPPN MO'A & & $\mathrm{x}$ & $x$ & & & $\mathrm{x}$ & & $\mathrm{xx}$ & $x$ & $\mathrm{x}$ & $x$ & & 17 \\
\hline $\begin{array}{l}\text { Expticas ou } \\
\text { Notivas }\end{array}$ & $\mathrm{x}$ & & $x x$ & $x$ & & $x x$ & $x$ & & & $x$ & & & 11 \\
\hline Vista para o Morro & & $x$ & & $x$ & & & & $x$ & & & & & 5 \\
\hline Carqueja & $x$ & & $x$ & & & $\mathrm{x}$ & & & & & & & 4 \\
\hline Basaltos & & $x$ & $x$ & & & & $x$ & & & & $x$ & & 5 \\
\hline Sarandi & $\mathrm{x}$ & $x$ & $x$ & & $x$ & $\mathrm{x}$ & & & $x$ & $\mathrm{x}$ & $x$ & & 14 \\
\hline Poso Lambari & & $x$ & $x$ & & $x$ & $\mathrm{x}$ & & $x$ & $x$ & $x$ & $x$ & & 16 \\
\hline Cafceiro do-mato & $x$ & & $x$ & & & $\mathrm{x}$ & & & & & & & 4 \\
\hline Furgo do as puro & $x$ & & $x x$ & $x$ & & $x x$ & $x$ & & & $x$ & $x$ & & 13 \\
\hline
\end{tabular}

Para esclarecer melhor quais pontos são mais relevantes para a IA construiu-se um gráfico de colunas onde os 6 pontos que se destacam foram selecionados. Observa-se a Figura $1 \mathrm{com}$ os pontos selecionados e os valores de atratividade. 


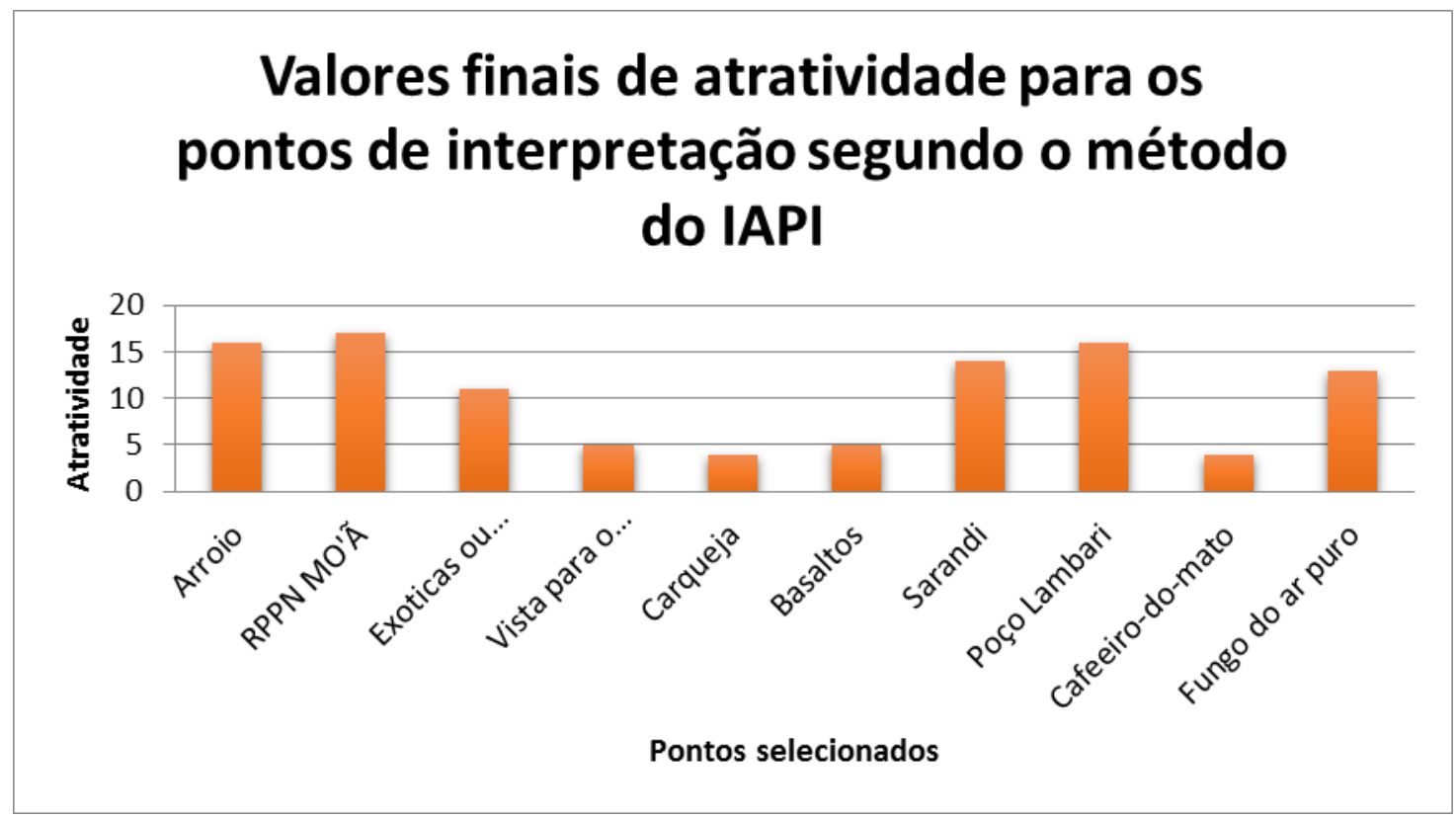

Figura 1: Valores finais de atratividade para os pontos de interpretação Trilha do Arroio Manuel Alves. Fonte: autores (2016)

Figure 1: Final values of attractiveness for interpretation points. Manuel Alves Arroio Trail. Source: authors (2016).

A última etapa se constituiu na elaboração de um meio interpretativo, no caso um folder (Apêndice $A$ ) e um guia prático (Apêndice B) que mostra os pontos selecionados pela pesquisa com sua breve interpretação e fotografia. Para a confecção desse folder e o guia foi utilizado o software GoogleEarth® e o programa de edição de imagem CorelDraw®.

\section{Resultados e Reflexões}

Ao considerar os estudos realizados por esta pesquisa, a RPPN Estadual MO'Ã tem um potencial relevante para o município de Itaara, porém ainda pouco explorado no sentido da IA, muito em função da sua recente instituição. Portanto esta pesquisa propõe como estratégia de leitura da paisagem da RPPN Estadual MO'Ã através de uma trilha interpretativa autoguiada, pois segundo o Material Manejo de Trilhas: Manual para Gestores (2008), uma trilha de até $2.500 \mathrm{~m}$, é considerada uma trilha de curta distância e é destinada a atividades recreativas e educativas.

Após três saídas de campo foi decidido o tópico interpretativo que foi a Mata Ciliar, tal tema abre um leque para a IA, pois pode-se abordar o tema sobrea importância da mata ciliar para a conservação dos recursos hídricos. Na Figura 2 observa-se o mapa de Localização da trilha do Arroio Manuel Alves. 


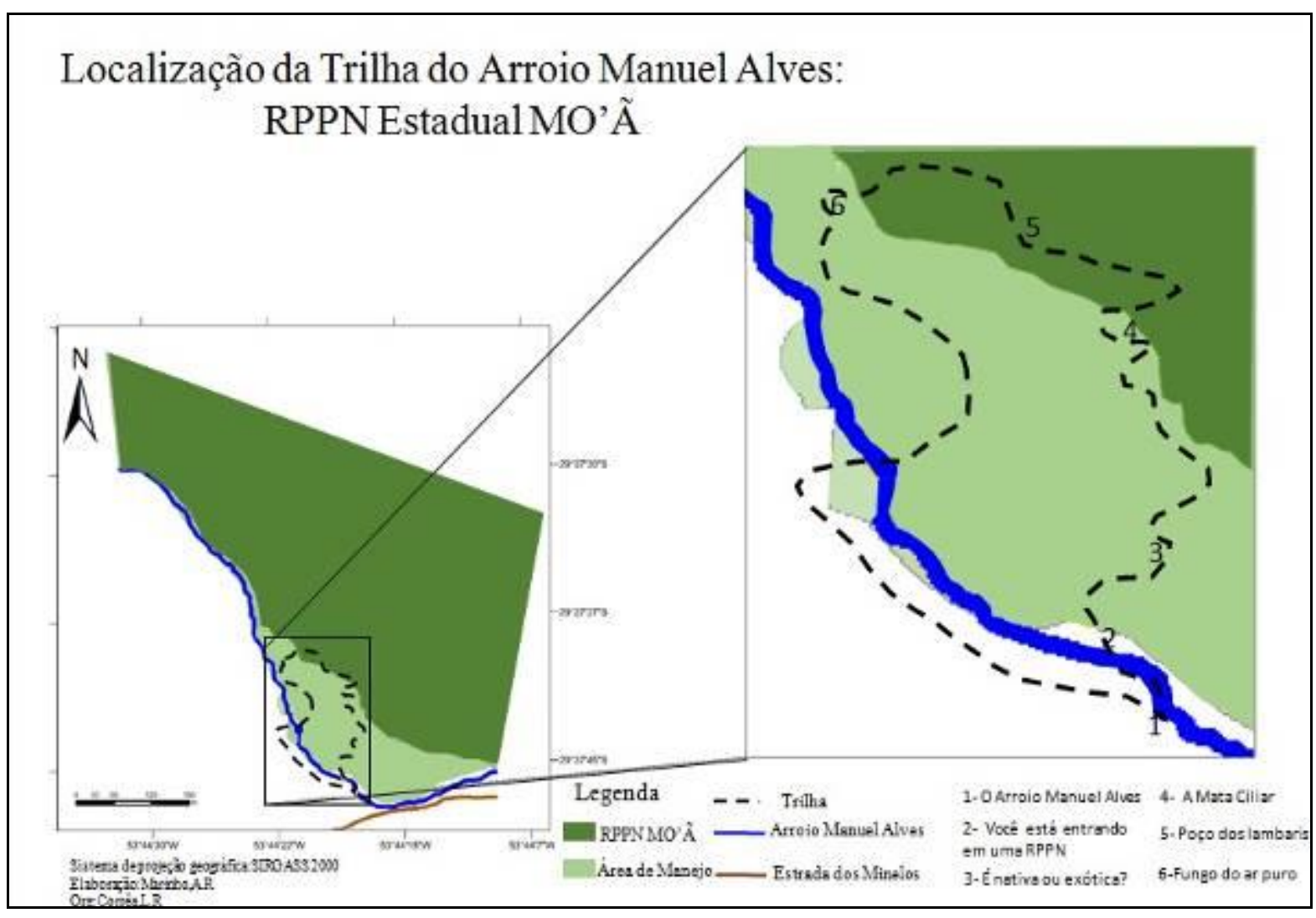

Figura 2: Mapa de Localização da Trilha do Arroio Manuel Alves. Fonte: Marinho, A.R.; Org.: Corrêa, L.R; (2016).

Figure 2: Manuel Alves Stream Trail Map. Source: Marinho, A.R.; Org.: Corrêa, L.R. (2016).

Foram elencados 6 pontos para uma trilha autoguiada de $1,5 \mathrm{Km}$ no entorno do rio que faz divisa da RPPN Estadual MO'Ã com outra propriedade. Em relação ao grau de dificuldade é considerada uma Trilha Moderada, pois seu percurso é inferior a $1.500 \mathrm{~m}$, exigindo esforço físico moderado, apresentando pequenos obstáculos, como desníveis, escadas, pedras, troncos, riachos, mas não exigindo técnica específica. A referente trilha tem a forma circular, possibilitando ao visitante voltar ao ponto inicial sem cruzar pelo mesmo caminho.

Em seguida os pontos selecionados e suas respectivas interpretações:

\section{Ponto 1: O Arroio Manuel Alves (29³7'46.36"S / 5344'18.13"O)}

No ponto 1 busca-se aguçar os sentidos do visitante, com o som e 0 tato, pois para acessar a RPPN Estadual MO'Ã necessita-se atravessar o rio, neste ponto o visitante é posto a sentir as rochas, basaltos do fundo do rio e o seu forte fluxo, podendo observar os matacões nas margens do rio, este que modifica a paisagem em cada enxurrada, portanto sensibilizar-se para a importância da conservação do patrimônio hídrico através da 
proteção da Mata Ciliar, e o respeito para com a força da natureza. O poder de transporte do rio, produz uma seleção granulométrica, desde os maiores blocos nas áreas de maior energia, até a deposição das areias mais finas e argila nos pontos de menor energia.

$\mathrm{Na}$ área existem vários canais de rede de drenagem que compõem a micro bacia hidrográfica do Arroio Manoel Alves, responsável pelo abastecimento domiciliar da população rural local e flutuante, população esta, que vem para Itaara nos períodos de verão em busca de lazer nos balneários da região, principal atração turística do município. O Arroio Manoel Alves é um dos afluentes do Arroio Grande, integrante da bacia hidrográfica do rio Vacacaí-Mirim, da região hidrográfica do Guaíba. Este rio tem características bem peculiares pela sua energia e capacidade de carga. A dinâmica fluvial desta bacia hidrográfica é caracterizada por canais de grande energia de transporte nas porções de maior inclinação da vertente, o que facilita a ocorrência de enxurradas em períodos chuvosos.

A RPPN Estadual MO'Ã está situada na margem esquerda da Bacia Hidrográfica do Arroio Manoel Alves. Na porção sul da propriedade, onde está incluída a trilha, encontram-se as menores cotas altimétricas, bem como as menores declividades isso reflete em uma perda de energia do rio em direção à jusante, a qual se pode afirmar que resulta em uma dinâmica de formação de ilhotas por deposição de blocos e matacões no leito do canal. Neste ponto pode-se ressaltar a importância da Mata Ciliar para o rio, em relação à manutenção da qualidade da água, a mata reduz o assoreamento e a força das águas que chegam aos rios, o que mantém sua qualidade ao impedir a entrada de poluentes para o meio aquático.

O Arroio Manoel Alves em época de chuva intensa (cerca de $336 \mathrm{~mm}$, em novembro de 2013), mostrou-se com grande vazão (KORMANN,2010). Em 2014 em função do fenômeno climático El nino houve uma maior concentração de chuvas, impedindo a entrada na RPPN Estadual MO'Ã, em função da ausência de uma ponte, pois a que foi construída pela Prefeitura Municipal de Itaara foi levada pelo rio (FERRARESE, 2016). Em 2015 moradores do entorno da propriedade ficaram ilhados em função do rompimento da ponte que passa por cima do rio que deságua no Arroio Manuel Alves (DIÁRIO DE SANTA MARIA,2015). Na Figura 3 pode-se analisar a dinâmica do Arroio Manuel Alves.

Neste ponto pode-se esclarecer os fatores que influenciam na dinâmica fluvial, como a pluviosidade, que consiste na quantidade de água que este rio recebe em dias de chuva. Para o Arroio Manuel Alves é determinante a quantidade de chuva. Outros fatores como infiltração, evapotranspiração também são importantes, para determinar a dinâmica do rio. 

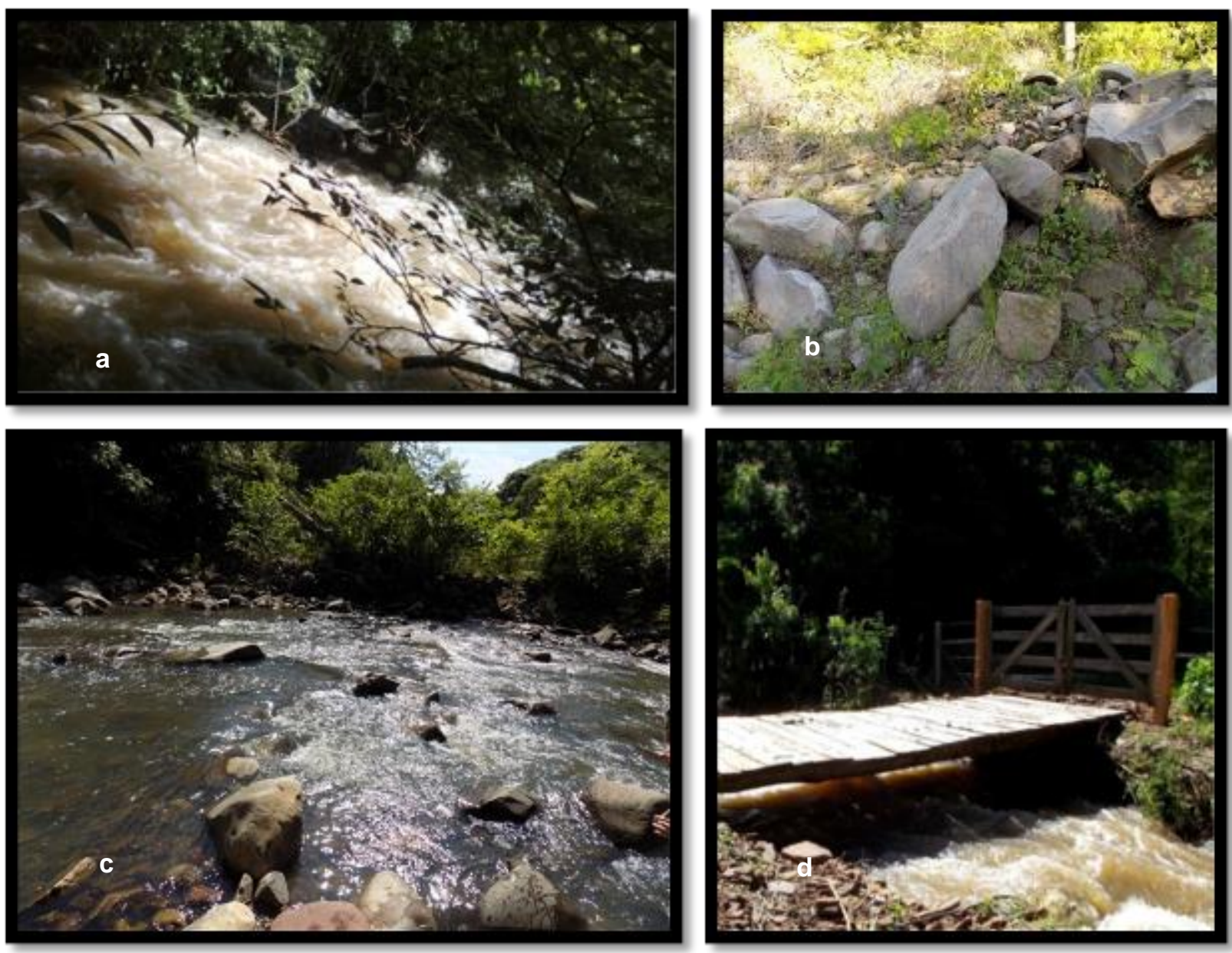

Figura 3: Arroio Manuel Alves:a) Vista do Arroio Manoel Alves em época de chuva intensa, cerca de 336 mm, em novembro de 2013; b) Matacões nas margens do arroio; c)Arroio Manuel Alves em 2016;d) Ponte de acesso a RPPN que foi levada pelo rio.

Fonte: acervo Fundação MO'Â.

Figure 3: Arroio Manuel Alves: a) View of Arroio Manoel Alves in heavy rainy season, about $336 \mathrm{~mm}$ in November 2013; B) Matacões on the banks of the stream; C) Arroio Manuel Alves in 2016; d) Access bridge to RPPN that was taken by the river.

Source: MO'ã foundation collection.

\section{Ponto 2: Você está entrando em uma Reserva Particular do Patrimônio Natural RPPN(29³7'46.44"S/53⒋'17.95"O)}

Neste ponto a informação não se refere a mata em si, mas sim às características da UC. Tem como objetivo explicar ao visitante o que são RPPNs, como são criadas, suas funções e importância, que são criadas por iniciativa dos proprietários, para conservar a natureza, ou seja, Reserva Particular do Patrimônio Natural (RPPN) é uma categoria de Unidade de Conservação criada pela vontade do proprietário, sem desapropriação de terra. No momento que decide criar uma RPPN, o proprietário assume compromisso com a conservação da natureza. Atividades recreativas, turísticas, de educação e pesquisa são permitidas na reserva, desde que 
sejam autorizadas pelo órgão ambiental responsável pelo seu reconhecimento (SNUC,2000).

A RPPN Estadual MO'Ã possui 21,02 há e foi instituída em 15 de junho de 2015, e tem por finalidade promover a proteção dos recursos ambientais e a conservação da diversidade biológica. Esta área foi doada pelo casal Rainer e Eleonora à Fundação MO'Ã Estudos e pesquisas para a Proteção e o Desenvolvimento Ambiental. A palavra MO'Ã significa proteger em tupi-guarani. Apesar de não estar inserida no tema específico da interpretação considerou-se que seria importante o esclarecimento ao visitante de que a área se trata de uma Unidade de Conservação e as características principais dessa categoria, já que a proposta é de uma trilha autoguiada. Na Figura 4 Placa indicativa na RPPN MO'Ã.

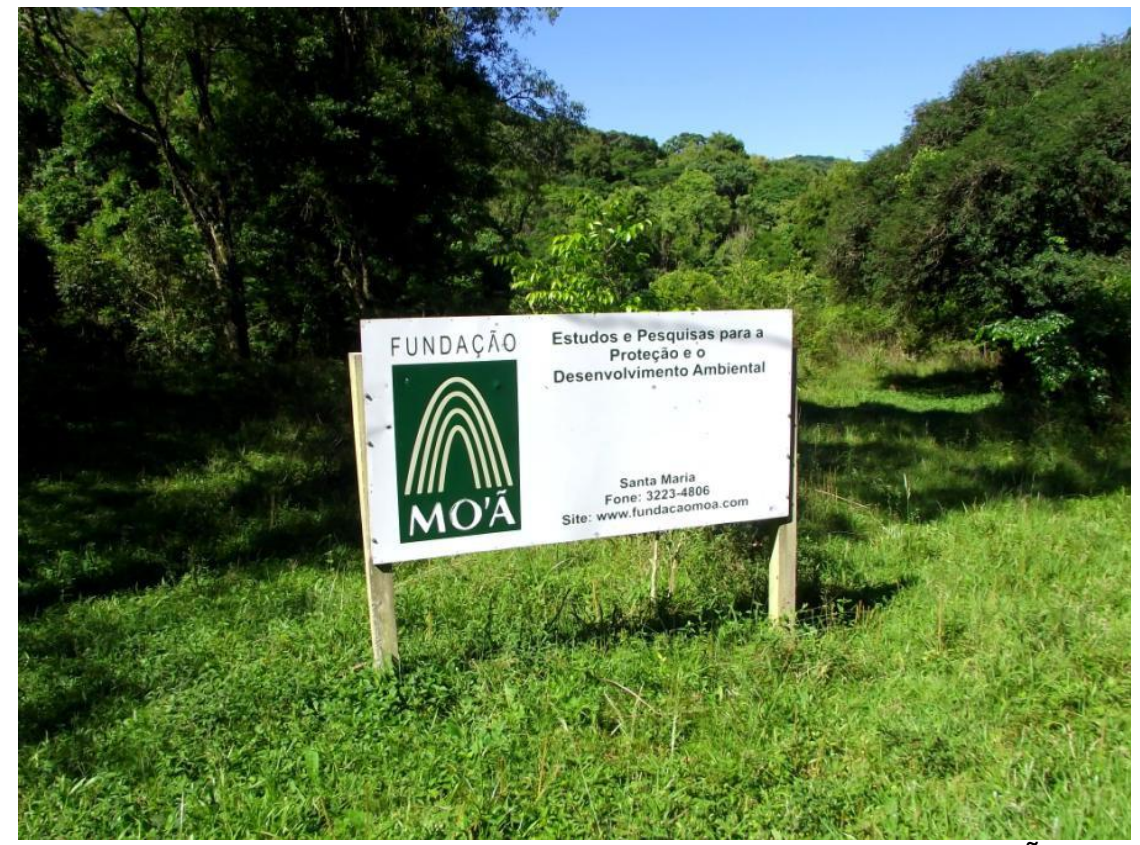

Figura 4: Placa indicativa da propriedade da Fundação MO'Ã.

Fonte: Acervo Fundação MO'Ã.

Figure 4: Indicative plate of the MO'ã Foundation.

Source: Mo'ã Foundation Collection.

Nesta área foram realizadas pesquisas relacionadas a Variáveis Climáticas,Solos e Levantamento Florístico, assim como visita de alunos da UFSM (SEMA,2014), destacando a importância desta UC para a pesquisa e Educação Ambiental, de forma que valorize a conservação da biodiversidade da área e promova a criação de novas UCs na região central do RS.

\section{Ponto 3: É nativa ou exótica? (29³7'44.41"S/ 5344'18.25"O)}

Neste ponto o visitante deve ser esclarecido inicialmente sobre as espécies nativas presente na Mata ciliar, que são aquela vegetação de uma determinada região que, durante milhares de anos, vêm interagindo com o ambiente e, assim, passou por um rigoroso processo de seleção natural gerando espécies geneticamente resistentes e adaptadas ao local onde 
ocorrem. E sobre as espécies exóticas que são aquelas introduzidas de outras regiões, como de outro país, por exemplo, as quais não sofreram esse processo de seleção natural e, dessa forma, não servem de substituto ideal para a flora nativa, uma vez que não desempenham as mesmas funções dentro do ecossistema (CAMPOS et al.,2006). A partir disso o visitante, já adentrando a mata ciliar, tem contato com uma variedade nativa do bioma da Mata Atlântica. A gimnosperma nativa Araucaria angustifólia, conhecida como Araucária é nativa do Rio Grande do Sul e dominante nas partes elevadas do Planalto, podendo ocorrer na Serra do Sudeste (FLORA DIGITAL,2009). No ponto 2 o objetivo é esclarecer sobre a importância de Unidades de Conservação como a RPPN Estadual MO'Ã para a proteção de espécie sem risco elevado de extinção como é o caso da Araucária. Nesta RPPN foram encontradas 277 taxa nativos do Brasil (FERRARESE,2016). E também para compreender o que são espécies nativas e os danos causados pela espécie exótica invasora em áreas naturais, como por exemplo a Uva do Japão (Hovenia dulcis Thunb.) originária da China, Japão e Coréia, atualmente é encontrada também no Brasil, Argentina, Paraguai, Uruguai, Estados Unidos, Cuba, Sul da Europa e Norte da África. Estes tipos de plantas, produzem descendentes em número muito elevado, que conseguem se dispersar a grandes distâncias da planta mãe, competindo com as espécies nativas. A dispersão de $H$. dulcis ocorre por seus frutos, carnosos ao madurar, com sabor doce e agradável. Em função disso as aves preferem seus frutos e não os das nativas. Diminuindo a disseminação das espécies nativas, (MAIEVES et al., 2015). Na Figura 5 observa-se duas espécies presentes da RPPN Estadual MO'Ã.
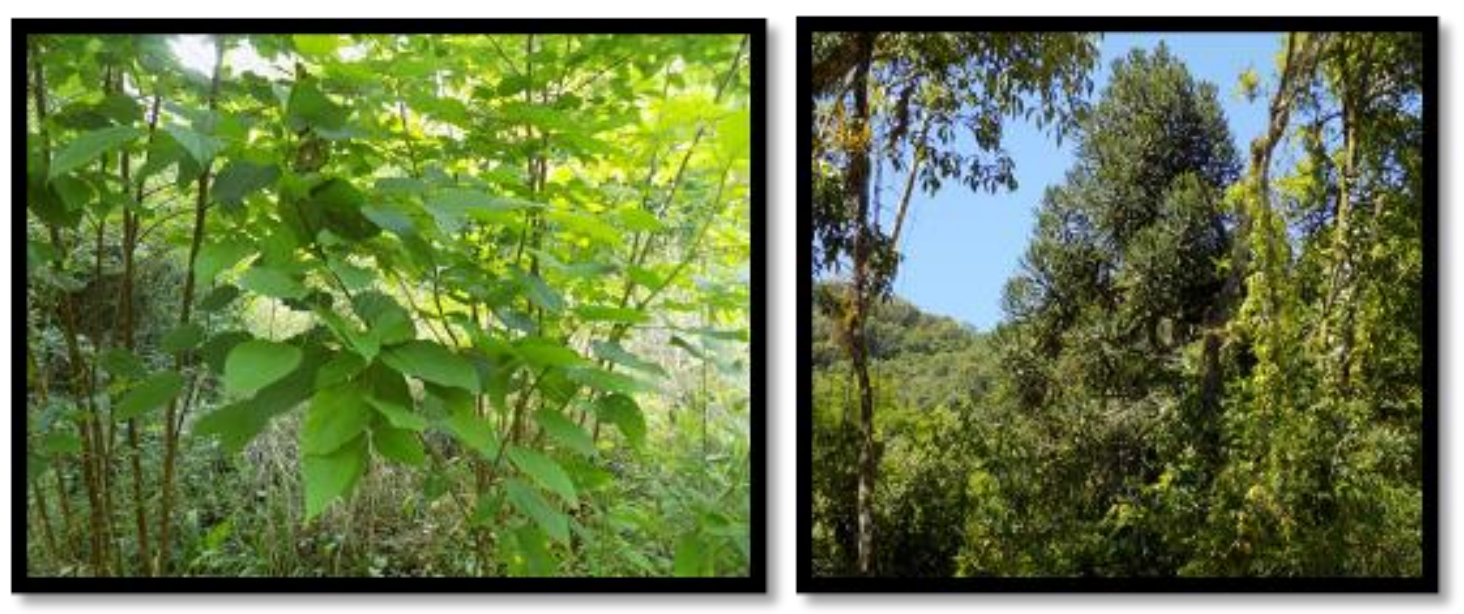

Figura 5: Exemplos de Espécies nativa e exóticas presentes na RPPN Estadual MO'Ã: a) Hovenia dulcis Thunb. b) Araucaria angustifolia. Fonte: Autores (2016).

Figure 5: Examples of native and exotic species present in the State RPPN MO'Ã: a) Hovenia dulcis Thunb. B) Araucaria angustifolia. Source: Authors (2016). 


\section{Ponto 4: Mata Ciliar e o Sarandi (29³7'41.24"S/ 5344'18.96"O)}

Neste ponto o objetivo é compreender a função da Mata Ciliar e suas características, que consiste na mata que se encontra ao longo dos cursos d'água (rios, córregos, lagos e lagoas). É caracterizada por ser bastante úmida, com abundante presença de samambaias e musgos. O nome "mata ciliar" vem do fato de serem tão importantes para a proteção de rios e lagos como são os cílios para nossos olhos, são como barreira que impede que a água do escoamento superficial escoe imediatamente para dentro do canal sendo liberada aos poucos para dentro do rio.

Amparada pelo Código Florestal Federal como "área de preservação permanente" deve respeitar uma extensão específica de acordo com a largura do rio, lago, represa ou nascente(BRAGA et al., 2003). Como podese observar na Figura 6.

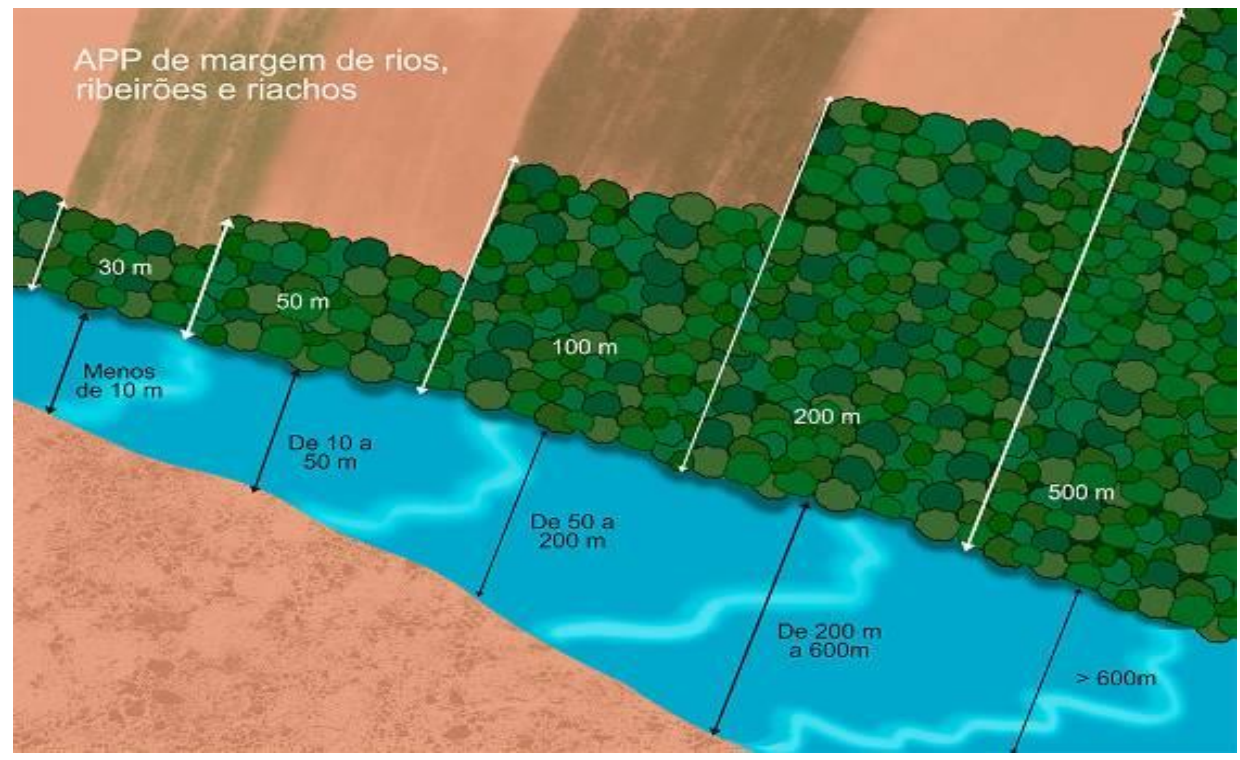

Figura 6: Representação da extensão da mata ciliar de acordo com a largura do rio. Fonte: Cartilha do Código Florestal (2016).

Figure 6: Representation of the extension of the ciliary forest according to the width of the river. Source: Forest Code Primer (2016).

De acordo com Nascimento (2001) há muitos benefícios oferecidos pela mata ciliar como:

-Proteção dos vegetais e animais, assim como os rios e nascentes e o solo com aumento da serapilheira, funciona como uma esponja que absorve a água evitando enxurradas

-Proporcionam abrigo a fauna, assim como alimento.

-Favorece o fluxo gênico dentro das populações

-Aumenta a resistência das margens dos rios, pelas raízes das arvores, evitando assoreamento.

-Atua como filtro reduzindo a contaminação dos cursos d'água por detritos

- Oferece benefícios sociais como espaço de lazer e contato direto com a natureza 
Em função disso neste ponto observa-se um arbusto característico de mata ciliar, o Sarandi (Colliguaja brasiliensisKlotzsch ex Baill.) encontrado nas margens do recursos hídricos (Figura 7), bem como em seu interior, mesmo quando estes possuem caráter temporário, permanecendo sem água em períodos de estiagem (FERRARESE, 2016). É presente no Brasil desde o RJ até o RS e no Uruguai, Paraguai e Argentina. Árvore que cresce apenas às margens dos rios, em áreas periodicamente alagadas. Possui importância por amenizar a erosão. Indicado para o reflorestamento das margens de rios. É comum uma parte das suas folhas cair no inverno (CEPPA, 2008).
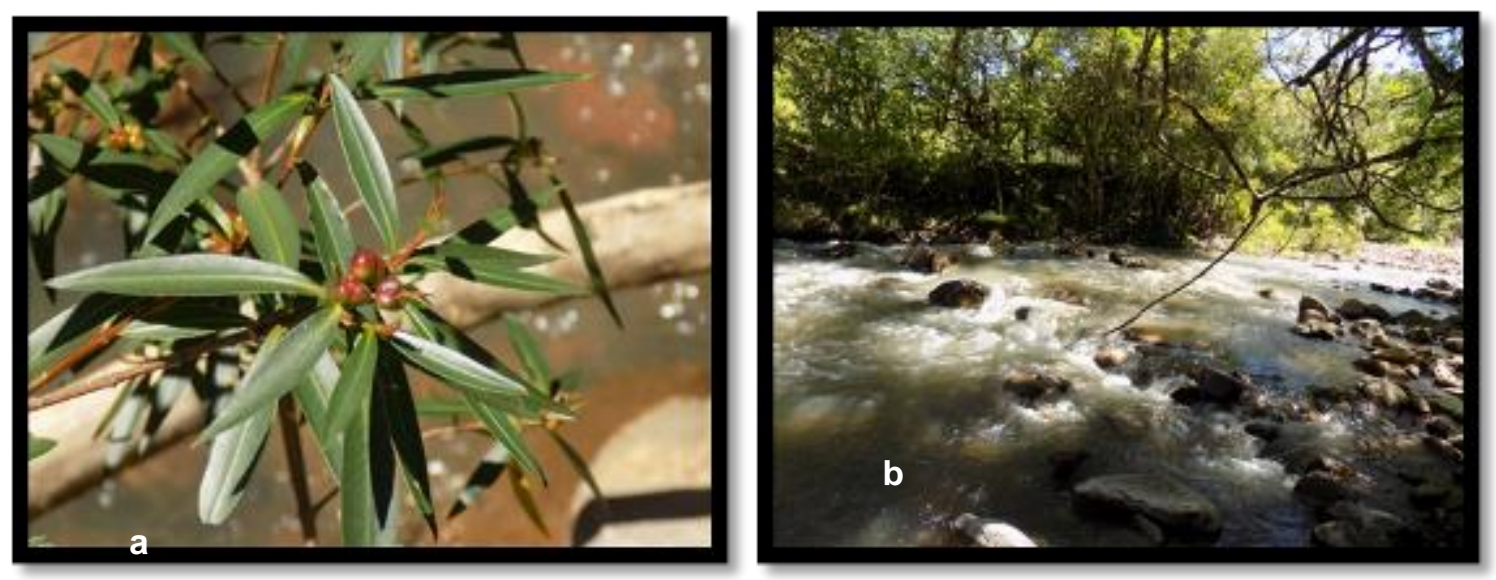

Figura 7: a) Sarandi-mata-olho presente na mata ciliar do Arroio Manuel Alves;

b) Mata ciliar no entorno do Arroio da RPPN Estadual MO'Ã. Fonte: Autores (2016).

Figure 7: a) Sarandi-kite-eye present in the ciliary forest of Arroio Manuel Alves;

b) Ciliary forest in the surroundings of the Arroio of the State RPPN MO'Ã.

Source: Authors (2016).

\section{Ponto 5: Poço dos lambaris (29³7'40.39"S/ 5344'19.84"O)}

Neste ponto o objetivo é compreender que a as várzeas são ambientes importantes para a manutenção do equilíbrio da dinâmica do rio, em tais condições a entrada e saída de sedimentos são equivalentes (BIGARELLA,2003) assim como do equilíbrio ecológico na RPPN Estadual MO'Ã. São elas que dissipam as forças erosivas do escoamento superficial de águas pluviais, funcionando como importantes controladores de enchentes e em época de chuva intensa forma pequenos córregos que deságuam no Arroio Manuel Alves, caracterizando canais entrelaçados, típicos de zonas montanhosas, com planície, formada a partir de depósitos coluvionares sob constante retrabalhamento pela complexa rede de canais de menor porte que são constantemente desativados/reativados de acordo com o período chuvoso (KORMANN et al., 2009). Após as chuvas os córregos secam e este pequeno poço se forma e nele se desenvolve um habitat de peixes de pequeno porte assim como anfíbios (Figura 19). 


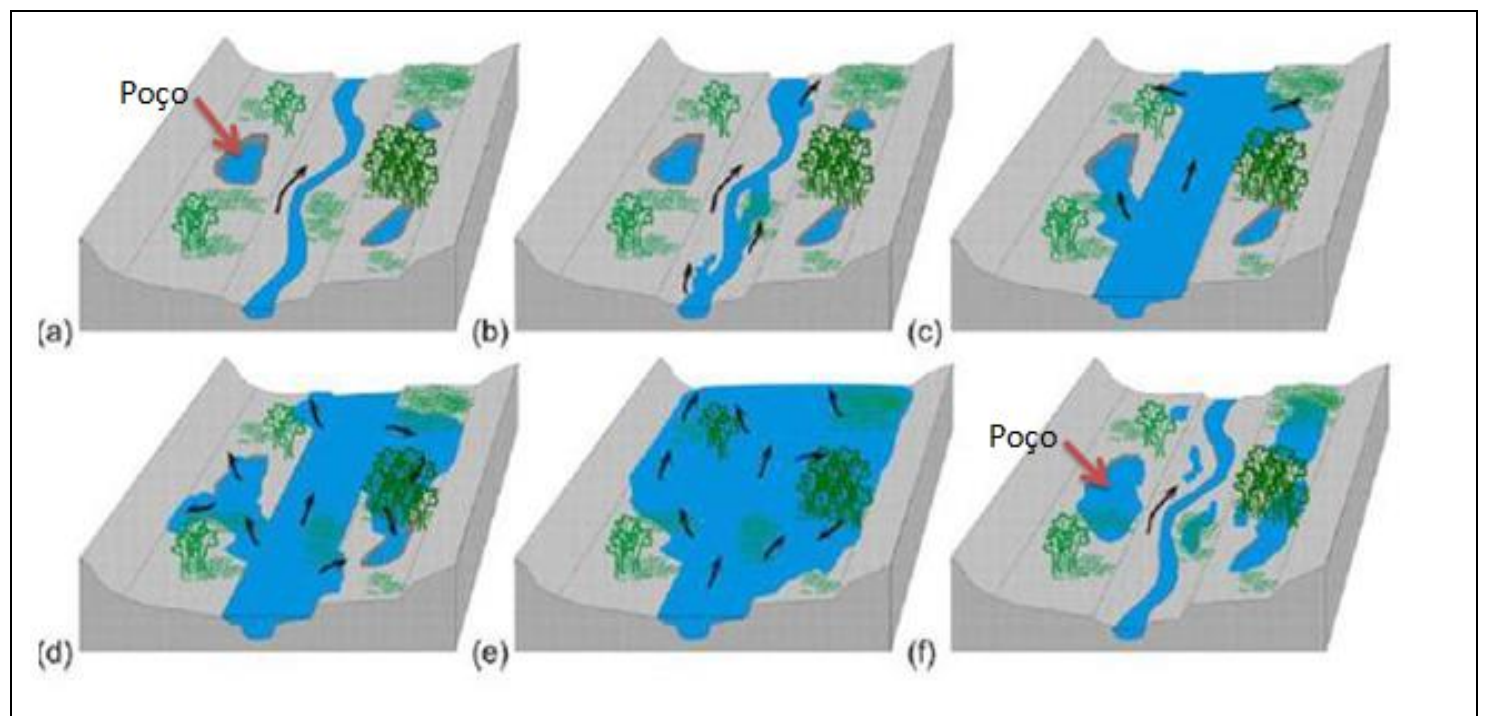

Figura 8: (a) Escoamento restrito à calha principal do rio, poço com pouca quantidade de água; (b) Início do extravasamento da calha; (c), (d), (e) Extravasamento da calha inunda a planície; (f) Após passagem da cheia, acréscimo do volume de água no poço.

Fonte: adaptado de PAZ (2010).

Figure 8: (a) Flow restricted to the main channel of the river, well with little amount of water; (B) Start of the extravasation of the gutter; (C), (d), (e) Extravasation of the gutter floods the plain; (F) After passing the flood, increase the volume of water in the well.

Source: Adapted from PAZ (2010).

Nesta parada o visitante pode desenvolver sua percepção sobre o meio, pois remete a um ambiente calmo de apreciação da vida de pequenas espécies, necessitando de atenção e silencio. Na Figura 9 um exemplo da beleza cênica presente na RPPN Estadual MO'Ã.

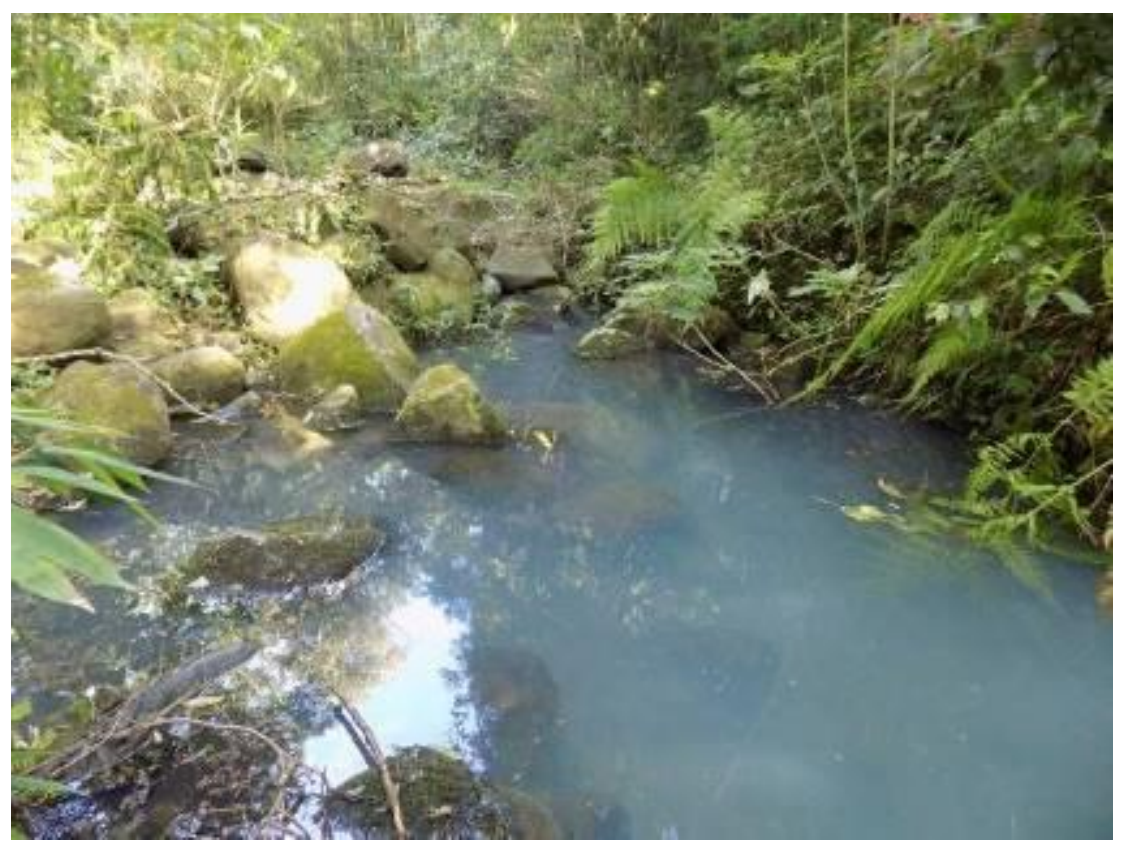

Figura 9: Poço formado pela inundação do Arroio Manuel Alves. Fonte: Autores (2016)

Figure 9: Well formed by the flood of Arroio Manuel Alves. Source: Authors (2016). 


\section{Ponto 6: Fungo do ar puro (29 $37^{\circ} 39.66^{\prime \prime S} / 53^{\circ} 44^{\prime 22.07 " O)}$}

Neste ponto o visitante deve compreender a importância da preservação da mata ciliar para o rio, para a qualidade da água, e para nossa saúde, na qualidade do ar. Nos grandes centros urbanos os poluentes atmosféricos são os grandes causadores de problemas na saúde humana, principalmente respiratórios.

A presença deste poluentes pode ser, muitas vezes, observada a partir da presença ou ausência de bioindicadores como os liquens. Para tanto deve-se observar as arvores e especificamente os seus troncos. No caso deste ponto percebe-se manchas rosas. Estas "manchas" são chamadas de liquens, que são seres vivos muito simples que constituem uma simbiose de um organismo formado por um fungo e uma alga; geralmente se proliferam nos substratos mais variados: sobre rochas, solo, casca das árvores e madeira. Podem ser de diversos tipos como Crostos o que é o caso deste ponto, onde o líquen fica preso no substrato, pode ser folioso tomando uma forma de folha, ou fruticoso tendo a forma de um arbusto. São seres pioneiros nas rochas nuas, dos solos de florestas queimadas e de escoadas vulcânicas. $O$ ar atmosférico puro é fator fundamental à sobrevivência dos liquens, assim como bromélias, já que estes se alimentam da água presente do meio, fixando elementos neles presentes, especialmente o nitrogênio (GONÇALVEZ, 2007 apud VICENTE, 2012).

Neste ponto podemos concluir que a qualidade do ar na RPPN Estadual MO'Á é boa pela presença do líquen na arvore. Na figura21a seguir observa-se a presença de manchas rosas no caule da arvore, que consiste no líquen.
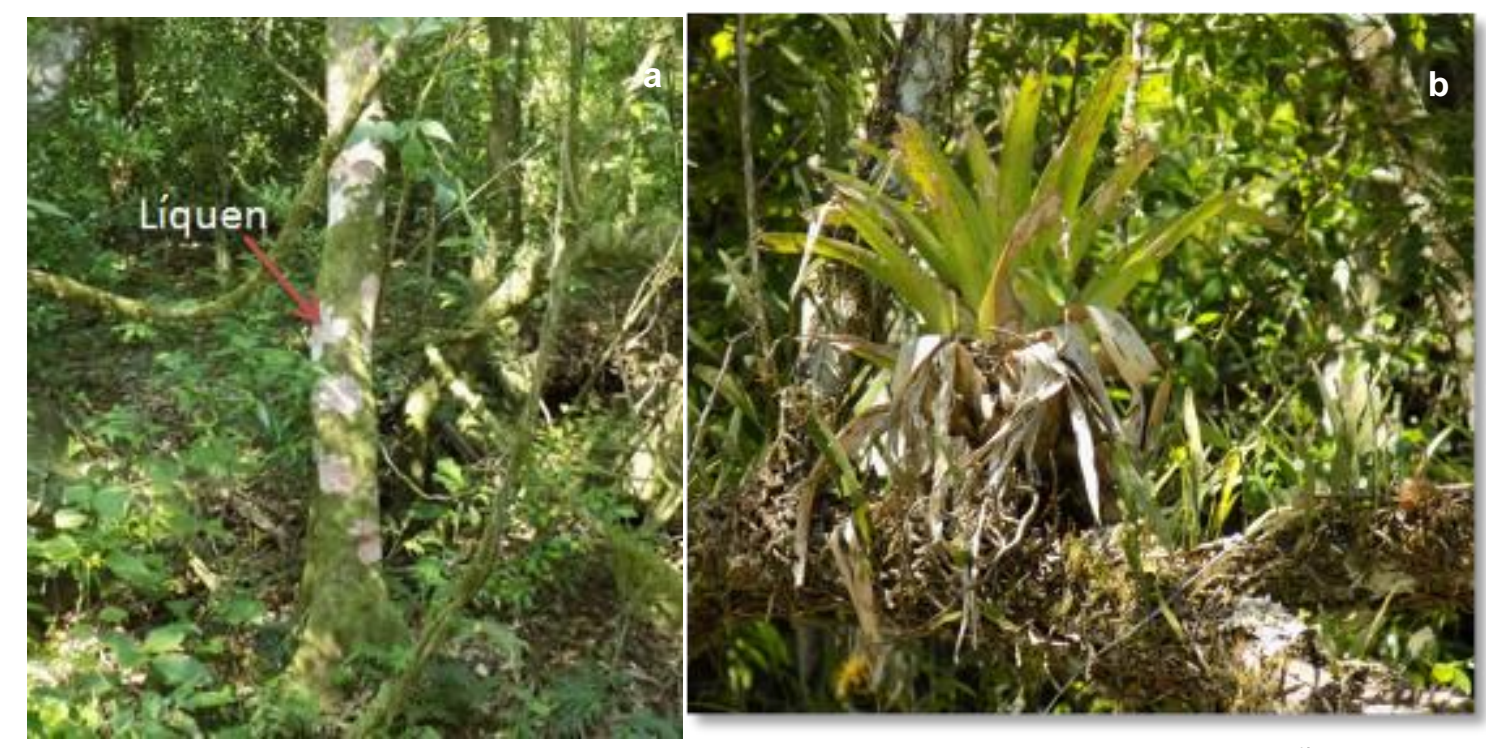

Figura 10: a) Líquen no caule da arvore; b) Bromélia presente na RPPN MO'Ã.

Fonte: Autores (2016).

Figure 10: a) Lichen on the stem of the tree; B) Bromeliad present in RPPN MO'Ã. Source: Authors (2016). 


\section{Considerações}

Afirmara partir dos trabalhos de campo realizados pode-se comprovar o grande potencial interpretativo presente na RPPN Estadual MO'Ã, assim como em todo o corredor ecológico da Quarta Colônia. Ações de IA se fazem necessárias para a valorização de tais potencialidades.

O acesso a propriedade através de uma ponte é de extrema relevância, pois um dos princípios da IA é o acesso e segurança do visitante, a ausência de uma ponte dificulta o acesso principalmente em períodos pós chuvas.

A trilha sugerida no presente trabalho tem como público alvo a comunidade escolar, mas nada impede que seja utilizada por visitantes em geral desde que siga o Plano de Manejo. Posteriormente a capacidade de carga da trilha deverá ser calculada, para minimizar impactos e subsidiar 0 Plano de manejo da RPPN Estadual MO'Ã.

Portanto com a presente pesquisa conclui-se que a informação é importante para IA, porém se usá-la de maneira isolada, ela será inútil e dispensável. Mas se traduzi-la de forma que conecte o visitante ao meio, será transformadora. A IA deve provocar sensações e instigar o visitante. Deve partir do contato direto com a natureza, para que alcance seu verdadeiro objetivo (PROJETO DOCES MATAS, 2002).

O Plano de Manejo, que "é um documento consistente, elaborado a partir de diversos estudos, incluindo diagnósticos do meio físico, biológico e social"(MMA,2016) está em fase de construção, tendo até 2020 para concluir-se, sendo que todas as pesquisas realizadas até então, deverão compor este Plano, assim como um Plano Interpretativo onde esta pesquisa se faz pioneira, este plano de manejo estabelece normas e restrições para uso da RPPN.

Destaca-se a necessidade de acessos e infraestrutura na propriedade para receber pesquisadores e visitantes, assim como um Centro de Interpretação e Pesquisas Ambientais (CIPA), que futuramente tornará a RPPN Estadual MO'Ã um local de referência de pesquisa e Educação Ambiental. Este centro deve conectar-se a esta trilha proposta e com as demais que serão construídas com seus tópicos e temas definidos.

A referente trilha poderá vir a ser guiada desde que haja um profissional preparado a guiar os visitantes.

\section{Referências}

BRAGA, A.R.; GRABHER, C; LAHÓZ, F.C.C; GOTARDI, K.R. Educação Ambiental para gestão de recursos hídricos: livro de orientação para 0 educador. São Paulo: Consórcio PCJ, 2003

BRASIL. Lei n. 9.985 de 18 de julho de 2000. Instituiu o Sistema Nacional de Unidades de Conservação da Natureza e dá outras providências. Presidência da República - Casa Civil, Brasília, DF, 18 jul. 2000. 
BIGARELLA, J.J. Estrutra e origem das paisagens tropicais e subtropicais. Florianópolis: Ed. Da UFSC, 2003

CAMPOS, J.B. et al. Unidades de Conservação: ações para a valorização da biodiversidade. Curitiba: Instituto Ambiental do Paraná, 2005.

CAPRA, F. A Teia da Vida: Uma Nova Compreensão Científica dos Sistemas Vivos. São Paulo: Cultrix, 1996.

CHAMI, L.; DEON, M.; SILVA, G.P. RPPN MO'Ã: Meios físico e biótipo. Disponível $<$ http://www.sema.rs.gov.br/upload/Estudo\%20T\%C3\%A9cnico.pdf>. Acesso em 06 de Julho de 2016

CHRISTOFOLETTI, A. Análise de Sistemas em Geografia. São Paulo: HUCITEC, 1979.

CENTRO DE EDUCAÇÃO, PESQUISA E PRESERVAÇÃO AMBIENTAL. Florística. Descrição de Espécies Florestais: CEPPA, 2008. Disponível em $<$ http://www.unicruz.edu.br/floristica/descricao.php $>$. Acesso em 13 de Nov. de 2016.

FERRARESE, M.D. Florística de uma Reserva Particular do Patrimônio Natural em fragmento de Mata Atlântica (Itaara, RS, Brasil). Dissertação (mestrado agrobiologia) 2016, 80p.

FLORA DIGITAL. Araucaria angustifolia (Bertol.) Kuntze. Disponível em http://www.ufrgs.br/fitoecologia/florars/open_sp.php?img=1179. Acesso em 14 de Nov. de 2016

KORMANN, T.C.; ROBAINA, L.E.S.; FOLETO, E.M. Mapeamento Geoambiental como subsídio à gestão de futura RPPN (Reserva Particular do Patrimônio Natural) em Itaara/RS. In: SIMPÓSIO BRASILEIRO DE GEOGRAFIA FÍSICA APLICADA, 13. 2009, Viçosa/MG. Anais... Viçosa: Universidade Federal de Viçosa, 2009. CD-ROM.

KORMANN, T.C.; THOMAS, B.L; NASCIMENTO, D.B.; FOLETO, E.M. Contribuição Geográfica na Criação de uma Reserva Particular do Patrimonio Natural (RPPN) em Itaara- RS. Revista Geografar, Curitiba, v. 5, n. 2, p. 13-31, jul./dez. 2010. Disponível em: $<$ http://revistas.ufpr.br/geografar/article/view/20138>. Acesso em 22 de jul. de 2016.

MAGRO, T.C.; FREIXÊDAS, V.M. Trilhas: como facilitar a seleção de pontos interpretativos. Circular Técnica IPEF n. 186, Setembro de 1998.

PROJETO DOCES MATAS. Manual de Introdução à Interpretação Ambiental. Belo Horizonte: IEF: IBAMA. Fundação Biodiversitas, 2002.

MAIEVES, H.A. et al. Uva-do-japão (Hovenia dulcis): Valor nutricional e aceitabilidade. Paraná, EMBRAPA, 2015. Disponível em $<$ http://ainfo.cnptia.embrapa.br/digital/bitstream/item/141814/1/ComunicadoTecnico-361-2015-29-03-2016.pdf>. Acesso em 20 de Nov. de 2016. 
MINISTÉRIO DO MEIO AMBIENTE. Consultas por UCs. Disponível em $<$ http://www.mma.gov.br/areas-protegidas/cadastro-nacional-de-

ucs/consulta-por-uc>. Acesso em 18 de Nov.2016.

NASCIMENTO, C.E.S. A importância das matas ciliares: rio São Francisco. Petrolina, PE: Embrapa Semiárido, 2001. Disponível em $<$ http://www.cpatsa.embrapa.br:8080/public eletronica/downloads/SDC179.p df $>$. Acesso em 10 de dez. de 2016.

SECRETARIA DO MEIO AMBIENTE. Instituto Florestal. Manejo de Trilhas: Um Manual para Gestores. São Paulo: IF Série e Registros, n.35. 2008.

SOUZA, L.P.M. Plano de gestão turística do Geossitio Gauritas-Caçapava do Sul/RS. 2014, 52f. Monografia (de graduação em Geografia). Universidade Federal de Santa Maria,2011.

TILDEN, F. Interpreting Our Heritage. The University of North Carolina Press, Chapel Hill. North Carolina, 1977.

THOMAS, B.L; NASCIMENTO, D.B; KORMANN, T.C; FOLETO, E.M. Zoneamento ambiental como subsídio à elaboração do plano de manejo da reserva particular do patrimônio da fundação MO'Ã em Itaara (RS). Londrina, 2011. Disponível em $<$ http://www.uel.br/revistas/uel/index.php/geografias. Acesso em 7 de julho de 2016

VICENTE, R.R. A pesquisa no ensino de biologia: avaliação da qualidade do ar utilizando liquens como bioindicadores. 2012. Monografia (de especialização em Ensino de Ciências). Universidade Tecnológica Federal do Paraná - Campus Medianeira. 2012.

Letícia Ramires Corrêa: Universidade Federal de Santa Maria, Santa Maria, RS, Brasil.

E-mail: leticiarcorrea@gmail.com

Link para o currículo Lattes: http://lattes.cnpq.br/3357786530501748

Adriano Severo Figueiró: Universidade Federal de Santa Maria, Santa Maria, RS, Brasil.

E-mail: adri.geo.ufsm@gmail.com

Link para o currículo Lattes: http://lattes.cnpq.br/0669013150421592

Data de submissão: 07 de março de 2017

Data de recebimento de correções: 31 de julho de 2017

Data do aceite: 31 de julho de 2017

Avaliado anonimamente 